\title{
Knowledge Spillover, Relative Wealth Seeking Motive and Government Expenditure Financing in Growth Analysis
}

\author{
Min-Liang Hsieh \\ College of Management \\ Fujian University of Technology \\ Fuzhou 350118, China \\ 2772805354@qq.com; leomin437@fjut.edu.cn
}

\begin{abstract}
This paper introduces the motive of the relative wealth seeking, which characterizes the entrepreneurship, into a knowledge-spillover-type endogenous growth model with a cashin-advance constraint on consumption purchases and investment goods. I attempt to reexamine the growth effect of the wasteful government expenditure expansion, financed by alternative distortionary tax schemes, including seigniorage, consumption tax and income tax.
\end{abstract}

Keywords- knowledge spillover; relative wealth seeking motive; government expenditure financing

\section{INTRODUCTION}

Innovation can be divided into three categories: product innovation, process innovation and organizational innovation. It's context could be related with an idea, a product or service, a process, a system or a device. However, no matter which one it is, the new innovation/knowledge will be spread someday, somehow in the future and then has a broad influence on the whole society. Specifically, knowledge spillover usually brings forth progress and development, so that the economic growth rate could be raised. Romer model [1], a classical endogenous growth model, exactly deals with this issue.

Entrepreneurship usually contain relative wealth seeking motive. As documented by Werhane [2, pp. 99-100], "In the WN (The Wealth of Nations), part of the motive for property and capital accumulation is the desire for approval or respect, as Smith recognizes that we tend to admire the rich and avoid the poor." Accordingly, a rat-race attitude of relative wealth seeking behavior leads individuals to unintentionally act on behalf of the growth prospects of the whole society.

In this paper, I introduce the relative wealth seeking motive into Romer [1]-type endogenous growth model. By such a modeling framework, I attempt to reexamine how a wasteful government expenditure expansion financed by alternative distortionary tax schemes, including seigniorage, consumption tax and income tax, affects the economic growth rate.

\section{LITERATURE REVIEW}

\section{A. Wasteful Government Expenditure under Endogenous} growth model

In previous endogenous growth studies, it is well understood that expansionary fiscal spending policies, financed by a non-distortion tax such as lump-sum tax or a tax that does not seriously discourage investment, can be used to stimulate economic growth through some important channels. Specifically, these channels of stimulating growth are either through increasing the quantity of production factors or indirectly through increasing marginal productivity of privately supplied production factors [2, 3, 4, 5, 6, 7]. Accordingly, it is curious that, when government spending neither enters agents' production function nor enters their utility function (i.e. do not helpful for production and consumption), is a "wasteful" and "non-lump-sum-taxfinanced" government spending expansion theoretically possible to promote the economic growth rate? In the onesector endogenous growth model, to our knowledge, Palivos and Yip [8] is the only study regarding examining the relation among wasteful fiscal spending, financing policy and economic growth rate/social welfare. In their generalized cash-in-advance (CIA) monetary growth model with a continuously balanced budget constraint, Palivos and Yip [8] let seigniorage rate and income tax rate be endogenous variables to finance a given expenditure-income ratio. They find that a seigniorage-financed government expenditure expansion has no (negative) growth effect when CIA constraint is imposed on consumption only (consumption and a fraction of investment). However, an income-tax-financed expansionary spending always leads to negative growth effect.

\section{B. Relative Wealth Seeking Motive}

In the representative-agent endogenous growth literature, a number of papers have investigated how the wasteful government spending affects economic growth. In their twosector model of endogenous growth, Devereux and Love [9] show that government spending may raise growth rate, but only if the spending policy is financed without tax distortions. Abandoning elastic labor supply in Devereux and Love [9], Chang, Tsai and Lai [10] introduce the role of the spirit of 
capitalism, or say the motive of wealth-induced social status seeking, to analyze the relation between public spending/finance and economic growth in general two-sector model. They show that if the spirit of capitalism is present, lump-sum-tax-financed increases in government spending reduces the economic growth rate, while the spirit of capitalism is absent, neutrality on growth rate will be obtained.

\section{THE MODEL}

We assume that the economy is a continuum of infinitelylived representative agents with unit mass and a government. Their settings are described as follows:

\section{A. Representative Agents}

All agents care not only about their consumption $c$ but also about their relative wealth, which is the determinant of relative social status. Specifically, we define relative wealth as the sum of real money balances $m$ and physical capital $k$, relative to the aggregate average $\bar{m}+\bar{k}$, i.e. $(m+k) /(\bar{m}+\bar{k})$. Identical households are endowed with the same positive amount of physical capital $k_{0}>0$ and nominal money balances $M_{0}>0$ at the initial date $t=0$. They all share the technology of production that is commonly available and seek to maximize the following lifetime utility:

$$
\operatorname{Max} \int_{0}^{\infty}\left[\ln c+\beta v\left(\frac{m+k}{\bar{m}+\bar{k}}\right)\right] e^{-\rho t} d t, \rho>0
$$

subject to:

$$
\begin{aligned}
& m=(1-\tau) y-(1+\delta) c-i-\pi m, \\
& y \equiv A k^{1-\varepsilon} \bar{k}^{\varepsilon}, A>0,0<\varepsilon<1, \\
& k=i, \\
& m=(1+\delta) c+i,
\end{aligned}
$$

where $\beta=$ a non-negative parameter reflecting the desire for social status, $\rho=$ subjective time preference rate, $y=$ real income, $\varepsilon=$ the non-negative parameter indicating externalities from aggregate capital, $A=$ a scale parameter, $\tau=$ the income tax rate, $\delta=$ the consumption tax rate, $i=$ investment and $\pi=$ the inflation rate. Following Corneo and Jeanne [11], the instantaneous status utility $v(\square)$ is increasing, differentiable and concave. Throughout the paper, the time subscript $t$ is omitted to simplify the notation. A dot over a variable is used to denote its time derivative.

Let $\lambda$ and $\lambda_{k}$ be the co-state variables associated with equations (2) budget constraint faced by the representative agent and (3) the law of motion governing physical capital, respectively. Meanwhile, let $\psi$ denote the multiplier associated with equation (4). Thus, by the current-value Hamiltonian optimization, we obtain the optimum conditions necessary for the representative agent:

$$
\begin{aligned}
& \frac{1}{c}=(\lambda+\psi)(1+\delta), \\
& \psi+\lambda=\lambda_{k}, \\
& \frac{\beta}{\bar{m}+\bar{k}} v^{\prime}\left(\frac{m+k}{\bar{m}+\bar{k}}\right)-\lambda \pi+\psi=-\lambda+\lambda \rho,
\end{aligned}
$$

$$
\frac{\beta}{\bar{m}+\bar{k}} v^{\prime}\left(\frac{m+k}{\bar{m}+\bar{k}}\right)+\lambda(1-\varepsilon)(1-\tau) A k^{-\varepsilon} \bar{k}^{\varepsilon}=-\lambda_{k}+\lambda_{k} \rho,
$$

together with equations (4.2), (4.3), and (4.4'), and the transversality conditions of $m$ and $k$ :

$\lim _{t \rightarrow \infty} \lambda m e^{-\rho t}=\lim _{t \rightarrow \infty} \lambda_{k} k e^{-\rho t}=0$.

\section{B. The Governmen}

We assume that the government maintains a continuously balanced budget as equation (9):

$$
G=T+\frac{M}{P},
$$

where $G, T, M$ and $P$ denote government expenditure, taxes, nominal money and the price level, respectively.

From the side of government expenditure, in order to ensure that the economy will follow a BGP, following Palivos and Yip [8], we specify government expenditure $G$ is a constant share $0<\gamma<1$ of income $y$. From the side of government revenue, we assume that the government levies taxes $T$ and prints money $M / P$ to finance public expenditure. The former includes income tax $\tau y$ and consumption tax $\delta c$ while the latter implies seigniorage $\mu \mathrm{m}$, where $\mu$ denotes the growth rate of money supply. Accordingly, equation (9) is rewritten as equation (10):

$$
\gamma A k^{1-\varepsilon} \bar{k}^{\varepsilon}=\delta c+\tau A k^{1-\varepsilon} \bar{k}^{\varepsilon}+\mu m .
$$

The policy experiment we conduct is that the government finances a permanent increase in government expenditureincome ratio, $\gamma$, by using alternative taxation schemes: seigniorage $\mu \mathrm{m}$, consumption tax $\delta c$ and income tax $\tau y$. Therefore, following Palivos and Yip [8], in each of the three financing policies, the corresponding tax rate $(\mu, \delta, \tau)$ is endogenously determined to finance government expenditure. Furthermore, for the analytical simplicity, following Palivos and Yip [8], we assume that the other tax rate is set to be zero when analyzing one type of the corresponding government expenditure financing. Additionally, the government spending aspect is abstracted from our analysis, i.e., the services of government are assumed not to enter the representative agent's utility or production function. Tax revenues are assumed to be wasted on useless government expenditures rather than to be rebated. 
Because the agents are assumed to be identical, in a symmetric equilibrium all agents own the same amount of money and capital. As a result, $\bar{k}=k$ and $\bar{m}=m$ are true in equilibrium.

On the other hand, by definition, the law of motion governing real money balances is:

$$
\stackrel{\square}{m}=(\mu-\pi) m \text {. }
$$

By combining equations (2), (3), (10) and (11) together, the goods market equilibrium condition is given as:

$$
k=(1-\gamma) A k-c .
$$

As a consequence, the perfect-foresight equilibrium of the macroeconomic economy is described by $\bar{k}=k, \bar{m}=m$, and equations (4), (5), (6), (7), (8), (10), (11) and (12).

Additionally, by differentiating equation (5) with respect to time and using the information of equation (6), we can derive

$$
\frac{c}{c}=-\frac{\lambda_{k}}{\lambda_{k}}-\frac{\delta}{1+\delta} \frac{\delta}{\delta}
$$

As shown by Chen, Hsu and Lu [12], the growth rates of relevant economic variables will be the same along a BGP in the monetary AK-variation model, we therefore define the following transformed variables as:

$$
X \equiv m / k, Z \equiv c / k \text { and } R \equiv \lambda_{k} / \lambda \text {. }
$$

In terms of the above stationary transformed variables, thus we can afford to derive and describe an equilibrium and further analyze the state change of this dynamic growth system on the impact of government expenditure size $(\gamma)$ increasing in a steady state.

Substituting equations (5) and (6) into equation (7), then equation (7), in terms of transformed variables $(Z, X$ and $R$ ), is rewritten as:

$$
\frac{\lambda}{\lambda}=\rho-\frac{\beta v^{\prime}(1) R Z(1+\delta)}{1+X}+\pi-(R-1) .
$$

Next, from equation (8), by combining equations (5) and (6) together, we can derive the evolution of the shadow price of real capital stock in terms of transformed variables as following:

$$
\frac{\lambda_{k}}{\lambda_{k}}=\rho-\frac{\beta v^{\prime}(1) Z(1+\delta)}{1+X}-\frac{(1-\varepsilon)(1-\tau) A}{R} .
$$

In addition, rewrite equation (12), and the growth rate of physical capital in terms of transformed variable $Z$, is therefore given as:

$$
\frac{k}{k}=(1-\gamma) A-Z \text {. }
$$

By the information of equations (3) and (12), (4) with transformed variables $Z$ and $X$, we can obtain:

$$
X=\delta Z+(1-\gamma) A .
$$

Therefore, after substituting equation (17) into equation (10), the continuously government balanced-budget constraint, in terms of $Z$, implies:

$$
\gamma A=\delta Z+\mu(\delta Z+(1-\gamma) A)+\tau A .
$$

Note that, since we assume that the other tax rate is set to be zero when analyzing one type of the corresponding government expenditure financing, equation (18) gives the alternative endogenous tax-financing rates $(\mu, \delta, \tau)$ as follows:

$$
\begin{gathered}
\mu^{(j)}=\left\{\begin{array}{ccc}
\frac{\gamma}{1-\gamma} & \text { as } & j=\mu, \\
0 & \text { as } & j=\delta, \tau,
\end{array}\right. \\
\delta^{(j)}=\left\{\begin{array}{ccc}
\frac{\gamma A}{Z} & \text { as } & j=\delta, \\
0 & \text { as } & j=\mu, \tau,
\end{array}\right. \\
\tau^{(j)}=\left\{\begin{array}{lll}
\gamma & \text { as } & j=\tau, \\
0 & \text { as } & j=\mu, \delta,
\end{array}\right.
\end{gathered}
$$

where the superscript $j$ of variables (hereafter) denotes the scheme corresponding to higher government expenditure, financed by $j(j=\mu, \delta, \tau)$.

\section{Steady States and Local Stability Properties}

Because the economy is characterized by $R=Z=0$ at steady-growth equilibrium, implying that there exists $(R, Z)$ (hereafter, the superscript, ${ }^{\wedge}$, denotes the BGP equilibrium value of the corresponding endogenous variables) such that the BGP equilibrium sustains, using equations (13), (14), (15) and (16), we obtain the following equations, along BGP:

$$
\begin{aligned}
& \frac{R}{R}=\frac{\lambda_{k}}{\lambda_{k}}-\frac{\lambda}{\lambda}=(R-1)\left(\frac{\beta v^{\prime}(1) Z\left(1+\delta^{(j)}\right)}{1+X}+1\right)-\frac{(1-\varepsilon)\left(1-\tau^{(j)}\right) A}{R}-\pi=0, \\
& \frac{Z}{Z}=\frac{c}{c}-\frac{k}{k}=-\rho+\frac{\beta v^{\prime}(1) Z\left(1+\delta^{(j)}\right)}{1+X}+\frac{(1-\varepsilon)\left(1-\tau^{(j)}\right) A}{R}-(1-\gamma) A+Z=0,
\end{aligned}
$$

where $\pi=\mu^{(j)}-(1-\gamma) A+Z$ can be derived from equations (11) and (16) along BGP, while $X=\delta^{(j)} Z+(1-\gamma) A$ is obtained from equation (17). In addition, the endogenous alternative tax-financing rates ( $\not, \hat{\delta}, \hat{\tau}$ ) can be found in equation (19- $i$ ), $i=1,2,3$, respectively.

Next, we attempt to examine the steady state and its local stability properties under alternative financing schemes and then conduct the long-run comparative statics analysis in the next Section. 
1) Seigniorage Financing Scheme

From equations (20) and (21), the steady state under the seigniorage financing scheme can be described by

$$
\begin{aligned}
& R+\frac{\beta v^{\prime}(1) Z(R-1)}{1+(1-\gamma) A}-\frac{1}{1-\gamma}-\frac{(1-\varepsilon) A}{R}+(1-\gamma) A-Z=0, \\
& -\rho+\frac{\beta v^{\prime}(1) Z}{1+(1-\gamma) A}+\frac{(1-\varepsilon) A}{R}-(1-\gamma) A+Z=0 .
\end{aligned}
$$

Accordingly, steady states $R$ and $Z$ would be obtained.

Linearizing the dynamic system (20) and (21) around the steady state yields:

$$
\left[\begin{array}{l}
\square \\
R \\
Z
\end{array}\right]=\left[\begin{array}{cc}
R\left(\frac{\beta v^{\prime}(1) Z}{1+(1-\gamma) A}+1+\frac{(1-\varepsilon) A}{R^{2}}\right) & R\left(\frac{(R-1) \beta v^{\prime}(1)}{1+(1-\gamma) A}-1\right) \\
Z\left(-\frac{(1-\varepsilon) A}{R^{2}}\right) & Z\left(\frac{\beta v^{\prime}(1)}{1+(1-\gamma) A}+1\right)
\end{array}\right]\left[\begin{array}{l}
R-R \\
Z-Z
\end{array}\right]
$$

The trace and determinant of Jacobian matrix in this system are then given by:

$$
\begin{aligned}
& \operatorname{Tr}\left(\mathbf{J}^{(\mu)}\right)=R\left(\frac{\beta v^{\prime}(1) Z}{1+(1-\gamma) A}+1+\frac{(1-\varepsilon) A}{R^{2}}\right)+Z\left(\frac{\beta v^{\prime}(1)}{1+(1-\gamma) A}+1\right)>0, \\
& \operatorname{Det}\left(\mathbf{J}^{(\mu)}\right)=R Z\left(\left(\frac{\beta v^{\prime}(1) Z}{1+(1-\gamma) A}+1\right)\left(\frac{\beta v^{\prime}(1)}{1+(1-\gamma) A}+1\right)+\frac{\beta v^{\prime}(1)(1-\varepsilon) A}{(1+(1-\gamma) A) R}\right)>0
\end{aligned}
$$

Accordingly, equations (23-1) and (24-1) imply that there exist two positive characteristic roots in this economy. As claimed in the literature of dynamic rational expectations models such as Burmeister [13], Buiter [14] and Turnovsky [15], because there are exactly two jump variables, $R$ and $Z$, in this system, corresponding to two positive unstable roots, there exists a unique perfect-foresight equilibrium path. The steady state equilibrium is locally determinate.

\section{2) Consumption Tax Financing Scheme}

From equations (20) and (21), the steady state under the consumption tax financing scheme can be described by

$$
\begin{aligned}
& (R-1)\left(\frac{\beta v^{\prime}(1)(Z+\gamma A)}{1+A}+1\right)-\frac{(1-\varepsilon) A}{R}+(1-\gamma) A-Z=0, \\
& -\rho+\frac{\beta v^{\prime}(1)(Z+\gamma A)}{1+A}+\frac{(1-\varepsilon) A}{R}-(1-\gamma) A+Z=0 .
\end{aligned}
$$

Accordingly, steady states $R$ and $Z$ would be obtained.

Taking a linear expansion of the dynamic system (20) and (21) around the steady state yields:

$$
\left[\begin{array}{l}
a \\
Z \\
Z
\end{array}\right]=\left[\begin{array}{cc}
R\left(\frac{\beta v^{\prime}(1)(Z+\gamma A)}{1+A}+1+\frac{(1-\varepsilon) A}{R^{2}}\right) & R\left(\frac{(R-1) \beta v^{\prime}(1)}{1+A}-1\right) \\
(Z+\gamma A)\left(-\frac{(1-\varepsilon) A}{R^{2}}\right) & (Z+\gamma A)\left(\frac{\beta v^{\prime}(1)}{1+A}+1\right)
\end{array}\right]\left[\begin{array}{l}
R-R \\
Z-Z
\end{array}\right] .
$$

The trace and determinant of Jacobian matrix in this system are then given by:

$$
\begin{aligned}
& \operatorname{Tr}\left(\mathbf{J}^{(\delta)}\right)=R\left(\frac{\beta v^{\prime}(1)(Z+\gamma A)}{1+A}+1+\frac{(1-\varepsilon) A}{R^{2}}\right)+(Z+\gamma A)\left(\frac{\beta v^{\prime}(1)}{1+A}+1\right)>0, \\
& \operatorname{Det}\left(\mathbf{J}^{(\delta)}\right)=R(Z+\gamma A)\left(\left(\frac{\beta v^{\prime}(1)(Z+\gamma A)}{1+A}+1\right)\left(\frac{\beta v^{\prime}(1)}{1+A}+1\right)+\frac{\beta v^{\prime}(1)(1-\varepsilon) A}{(1+A) R}\right)>0 .
\end{aligned}
$$

Accordingly, it implies that there exist two positive characteristic roots in this economy. Therefore, a unique perfect-foresight equilibrium path exists.

\section{3) Income Tax Financing Scheme}

From equations (20) and (21), the steady state under the income tax financing scheme can be described by

$$
\begin{aligned}
& (R-1)\left(\frac{\beta v^{\prime}(1) Z}{1+(1-\gamma) A}+1\right)-\frac{(1-\varepsilon)(1-\gamma) A}{R}+(1-\gamma) A-Z=0, \\
& -\rho+\frac{\beta v^{\prime}(1) Z}{1+(1-\gamma) A}+\frac{(1-\varepsilon)(1-\gamma) A}{R}-(1-\gamma) A+Z=0 .
\end{aligned}
$$

Accordingly, steady states $R$ and $Z$ would be obtained.

Linearizing the dynamic system (20) and (21) around the steady state yields:

$$
\left[\begin{array}{l}
R \\
Z
\end{array}\right]=\left[\begin{array}{cc}
R\left(\frac{\beta v^{\prime}(1) Z}{1+(1-\gamma) A}+1+\frac{(1-\varepsilon)(1-\hat{\tau}) A}{R^{2}}\right) & R\left(\frac{(R-1) \beta v^{\prime}(1)}{1+(1-\gamma) A}-1\right) \\
Z\left(-\frac{(1-\varepsilon)(1-\hat{\tau}) A}{R^{2}}\right) & Z\left(\frac{\beta v^{\prime}(1)}{1+(1-\gamma) A}+1\right)
\end{array}\right]\left[\begin{array}{l}
R-R \\
Z-Z
\end{array}\right],
$$

The trace and determinant of Jacobian matrix in this system are then given by:

$$
\begin{aligned}
& \operatorname{Tr}\left(\mathbf{J}^{(\tau)}\right)=R\left(\frac{\beta v^{\prime}(1) Z}{1+(1-\gamma) A}+1+\frac{(1-\mathcal{E})(1-\hat{\tau}) A}{R^{2}}\right)+Z\left(\frac{\beta v^{\prime}(1)}{1+(1-\gamma) A}+1\right)>0, \\
& \operatorname{Det}\left(\mathbf{J}^{(\tau)}\right)=R Z\left(\left(\frac{\beta v^{\prime}(1) Z}{1+(1-\gamma) A}+1\right)\left(\frac{\beta v^{\prime}(1)}{1+(1-\gamma) A}+1\right)+\frac{\beta v^{\prime}(1)(1-\varepsilon)(1-\hat{\tau}) A}{(1+(1-\gamma) A) R}\right)>0 .
\end{aligned}
$$

Equations (23-3) and (24-3) imply that there exist two positive characteristic roots in this economy and there exists a unique perfect-foresight equilibrium path.

Summarizing, no matter which financing policies the government adopts, there always exist two positive characteristic roots in the economy corresponding to two jump variables, $R$ and $Z$ in this model. As a consequence, there exists a unique perfect-foresight equilibrium solution. It makes us ensure that the validity of comparative statics holds in the next Section.

\section{Growth Effects}

This section attempts to examine the growth effects of a permanent increase in the size of government expenditure $\gamma$ under alternative financing schemes. 
Let $\hat{\theta}$ be the steady-state growth rate. From equations (4.16), we then know that the balanced growth rate is given as

$$
\hat{\theta}=(1-\gamma) A-Z,
$$

where $\hat{\theta}$ is assumed to be positive.

Differentiating equation (25) with respect to $\gamma$, we can derive the growth effects of the higher government expenditure-income ratio, financed by alternative financing schemes, as follows:

$$
\left(\frac{d \hat{\theta}}{d \gamma}\right)^{(j)}=-A-\left(\frac{d Z}{d \gamma}\right)^{(j)},
$$

where the first term $-A$ implies that an increase in wasteful government expenditure reduces the amount of resources available and then affects the economic growth rate. We call this channel the resources withdrawal channel, which generates a negative growth effect. The second term, $\frac{d Z}{d \gamma}$, represents the response of consumption-capital ratio impacted by government spending shock. Through which, the induced effect of an expansion in government expenditure via alternative financing channels thus be reflected.

These analyses proceed as follows:

1) Seigniorage Financing Scheme

$$
\begin{aligned}
& \left(\frac{d \hat{\theta}}{d \gamma}\right)^{(\mu)}=-A-\left(\frac{d Z}{d \gamma}\right)^{(\mu)} \\
= & \frac{-A R Z}{\operatorname{Det}\left(\mathbf{J}^{(\mu)}\right)}\left(\frac{\beta v^{\prime}(1)(1+\hat{\theta})}{(1+(1-\gamma) A)^{2}}\left(\frac{\beta v^{\prime}(1) Z}{1+(1-\gamma) A}+1+\frac{(1-\varepsilon) A}{R}\right)+\frac{1-\varepsilon}{(1-\gamma)^{2} R}\right)<0
\end{aligned}
$$

Equation (26-1) unambiguously indicates that seignioragefinanced spending-growth effect is negative. Moreover, this negative result is not correlated with the magnitude of the desire for the relative wealth-induced social status and that of production externalities.

2) Consumption Tax Financing Scheme

$$
\left(\frac{d \hat{\theta}}{d \gamma}\right)^{(\delta)}=-A-\left(\frac{d Z}{d \gamma}\right)^{(\delta)}=0,
$$

Equation (26-2) tells us that, an increase in consumptiontax-financed government spending has neutral effect on the economic growth rate, even if we additionally consider that the CIA constraint is imposed on all investment goods.

3) Income Tax Financing Scheme

$$
\left(\frac{d \hat{\theta}}{d \gamma}\right)^{(\tau)}=-A-\left(\frac{d Z}{d \gamma}\right)^{(\tau)}
$$

$$
\begin{gathered}
=\frac{-A R Z \bar{Z}}{\operatorname{Det}\left(\mathbf{J}^{(\tau)}\right)}\left[\frac{\beta v^{\prime}(1)}{(1+(1-\gamma) A)^{2}}\left(\left(\frac{\beta v^{\prime}(1) Z}{1+(1-\gamma) A}+1\right)(1+\hat{\theta})+\frac{(1-\varepsilon)(1-\hat{\tau}) A(1-\gamma)}{R}\right)\right. \\
\left.+\frac{1-\varepsilon}{R}\left(\frac{\beta v^{\prime}(1) Z}{1+(1-\gamma) A}+1\right)\right]<0,
\end{gathered}
$$

From equation (26-3), we know that a permanent increase in income-tax-financed government expenditure is always growth retarding. This is because that the tendency of retarding capital-accumulation remains unchanged when we consider the CIA constraint imposed on investment. This result is also consistent with that of Paliovs and Yip [8] even though I introduce the relative wealth seeking motive into the model.

\section{CONCLUDING REMARKS}

This paper introduces the relative wealth seeking motive into Romer [1]-type endogenous growth model. I reexamine the growth effects of a permanent expansion in wasteful government expenditure, which is financed by alternative distortionary tax schemes, including seigniorage, consumption tax and income tax. In the seigniorage financing scheme, although a positive growth effect could be resulted from the higher wasteful government expenditure under the production externalities (knowledge spillover) environment with the relative status-seeking motive, this effect will be eroded fully if all investment goods are subject to the cash-in-advance constraint. When a CIA constraint imposed on all investment as well as consumption, all investment goods have to be purchased out of existing money balances whose value is eroded by higher inflation. Therefore, the gains of asset's allocation-adjustment become lower. As a result, CIA, instead of the role of the motive of relative wealth seeking, plays an important role in determining the spending-growth effect under the seigniorage financing scheme. In the consumption tax financing mode, even though the model considers the situation where all investment is liquidity constrained, agent still has no incentive to change his (her) assets' allocation due to their constant rate of return, and the steady-state growth rate of the economy is immune to changes in the public expenditure. Additionally, in the income tax financing mode, I find that the growth effect of an expansion in government expenditure is still negative.

\section{References}

[1] P.M. Romer, "Increasing returns and long run growth." Journal of Political Economy, 1986(94), pp. 1002-1038.

[2] P.H. Werhane, "Adam Smith and his legacy for modern capitalism" (Oxford University Press, New York), 1991.

[3] R.J. Barro, "Government spending in a simple model of endogenous growth." Journal of Political Economy, 1990(98), pp. S103-S125.

[4] S.J. Turnovsky, "Fiscal policy, elastic labor supply, and endogenous growth." Journal of Monetary Economics, 2000(45), pp. 185-210.

[5] S.L. Baier and G. Glomm, "Long-run growth and welfare effects of public policies with distortionary taxation." Journal of Economic Dynamics and Control, 2001(25), pp. 2007-2042..

[6] D.I.A. Wöhrmann, "Fiscal policy in a Lucasian general equilibrium model with productive government spending." Annals of Operations Research, 1999(88), pp. 47-64. 
[7] R. Aísa and F. Pueyo, "Government health spending and growth in a model of endogenous longevity." Economics Letters, 2006(90), pp. 249253.

[8] T. Palivos and C.K. Yip, "Government expenditure financing in an endogenous growth model: A comparison." Journal of Money, Credit, and Banking, 1995(27), pp. 1159-1178.

[9] M.B. Devereux, A.C. Head, and B.J. Lapham, "Government spending and welfare with returns to specialization." Scandinavian Journal of Economics, 2000(102), pp. 547-561.

[10] W.Y. Chang, H.F. Tsai, and C.C. Lai. "Taxation, growth, and the spirit of capitalism." European Journal of Political Economy, 2004(20), pp. 1011-1025.

[11] G. Corneo and O. Jeanne, "On relative wealth effects and the optimality of growth.” Economics Letters, 1997(54), pp. 87-92.

[12] B.L. Chen, M. Hsu, and C.H. Lu, "The dynamic welfare cost of inflation tax and consumption tax in a cash-in-advance model." Taiwan Economic Association Annual Conference, 2008, Taipei, Taiwan.

[13] E. Burmeister, "On some conceptual issues in rational expectations modeling." Journal of Money, Credit, and Banking, 1980(12), pp. 800812.

[14] W.H. Buiter, "Saddlepoint problems in continuous time rational expentations models: A general method and some macroeconomic examples." Econometrica, 1984(52), pp. 665-680.

[15] S.J. Turnovsky, Methods of Macroeconomic Dynamics, Cambridge, MA: MIT Press.1995. 